\title{
(Des)motivación y drogas: un análisis de las campañas de prevención en España (1987-2007)
}

\author{
(Des)motivation and Drugs: an Analysis of the Prevention \\ Campaigns in Spain (1987-2007)
}

\author{
Juan Carlos Checa Olmos \\ y María José González Moreno \\ Universidad de Almería
}

\section{RESUMEN}

El objetivo de este artículo es analizar el grado de adecuación de las campañas publicitarias para la prevención del consumo de drogas en España. Para ello, se han revisado los mensajes de las campañas televisadas por la FAD (Fundación Antidroga) desde el año 1987 hasta el 2007. El contenido de esas campañas ha sido comparado con las motivaciones para el consumo de drogas que ofrecen los informes bianuales de Los Andaluces ante las drogas (1987-2007). Los resultados muestran que el discurso esgrimido en las campañas no está estrechamente conectado con las motivaciones aludidas en el consumo de drogas. En consecuencia, se precisa de una estrategia de prevención que profundice en la desmotivación de los usuarios.

Palabras clave: Motivaciones, Drogas, Medios de comunicación, Publicidad, Prevención.

\section{SUMMARY}

The aim of this article is to analyze and frame the level of efficacy and adequacy of publicity campaigns for the prevention of drug use in Spain. To this end, the contents of the messages used by the FAD (Antidrug Foundation) in television campaigns broadcast between 1987 and 2007 have been reviewed. The content of these campaigns has also been linked to the progress and motivation of drug users through two decades, using the biannual surveys of Los Andaluces ante las drogas. The results show that the discourse followed in these campaigns has no relation whatsoever with the said motivations linked with drug abuse. Consequently, a strategy is required which will have an impact on discouraging and dissuading drug users.

Key words: Motivations, Drugs, Mass Media, Advertising, Prevention.

\section{INTRODUCCIÓN}

Uno de los aspectos que más se ha analizado en el consumo de drogas ha sido todo aquello que tiene que ver con las motivaciones, dando lugar a una vasta y variada literatura científica (véanse, entre otros, Balado 1980a y b, Berrocal 2001, García y otros 2006). En primer lugar, destacan los estudios que se centran en las razones 
por las cuales los consumidores acceden a tratamientos de desintoxicación, al abandono y la abstinencia del consumo de drogas, o a la incorporación a procesos de deshabituación y reinserción social (véanse, entre otros, Cosden y otros 2006; Gideon 2010; Longshore y Teruya 2006; Simoneau y Bergeron 2003; Simoneau y otros 2004). En segundo lugar, existe un gran número de investigaciones relacionadas con las consecuencias que implica el consumo drogas, en especial el síndrome amotivacional (véanse, entre otros, Baumrind y Moselle 1985; Dreher 1983; Lynskey y Hall 2000). Tampoco faltan autores que señalan que las motivaciones esgrimidas para el consumo de drogas evolucionan, lo que implica una perspectiva longitudinal en el estudio de las argumentaciones (Korcha y otros 2011). En cualquier caso, encontramos que la búsqueda de sensaciones y experiencias nuevas, la necesidad de aceptación e integración social, las actitudes desafiantes y arriesgadas del individuo, la emoción que implica un cambio de percepción psíquica, la automedicación y la añoranza hacia estados que promueven la ensoñación podrían ser razones para el uso de sustancias psicoactivas (Leon 1986; Romaní 2004). De esta forma, tampoco sería desatinado afirmar que el consumo de drogas se mantiene y perpetua en el tiempo en relación directa a la capacidad que tienen las diferentes sustancias de proporcionar algunos de los efectos anteriormente señalados, a las circunstancias que envuelven el ritual de consumo de drogas, o a la propia situación anímica del usuario; o lo que es igual, a los motivos para su consumo. Más aún, Spencer y Navaratnam (1980) manifiestan que el consumo de drogas, especialmente en poblaciones juveniles, está más relacionado con la arrogancia precoz, con un sistema de creencias propio y con el amparo que propician unos mensajes cautivadores sobre las drogas, difundidos habitualmente entre iguales. Incluso, otros explicarán el consumo a partir de las expectativas que esperan obtener con su uso y con ciertas circunstancias contextuales, como el medio ambiente, la disponibilidad, los medios económicos, los grupos de pares y los medios de comunicación (Boys y otros 1999).

Junto a este proceso motivacional se ha desarrollado, paralelamente, una estrategia educativa, encabezada por los medios de comunicación ${ }^{1}$, para tratar de frenar el consumo de drogas (García 1996). No obstante, los consumidores de drogas consideran poco influyentes las informaciones de los medios, puesto que la mayor influencia vendría desde los grupos de pares. Esto explicaría, a su vez, la cuestionable efectividad de las campañas preventivas (Costa y Pérez 1989). Dicho de otro modo, el poder de los medios de comunicación sobre la acción de consumir drogas se pone en entredicho, puesto que, en muchas ocasiones, lo que se consigue es más un refuerzo de la opinión favorable al consumo de drogas, que un cambio de actitud real. Por eso, no faltan investigaciones que afirman que la mayoría de los programas de prevención del consumo de drogas no son efectivos (European Monitoring Centre for Drugs and Drug Addiction 2006; Stanojlovic 2011). E incluso, se habrían observa-

\footnotetext{
${ }^{1}$ Las propuestas tratan de que los consumidores, o potenciales consumidores, interioricen las consecuencias negativas de su uso. Más concretamente, la orientación mediática de las drogas ha estado clasificada en cuatro modelos teóricos: el jurídico-moral, el médico-sanitario, el psicosocial y el sociocultural. Aunque en la actualidad parece imponerse un modelo más integrador como el biopsicosocial (Antón 1999). De igual modo, las campañas de medios masivos de comunicación que promueven la prevención de drogadicción apuntan hacia cuatro tipos de audiencias: juventud, padres, mujeres y los ancianos (Bandy y President 1983).
} 
do efectos contrarios a los deseados, debido, sobre todo, a que no se conocen las características precisas para conseguir programas de prevención adecuados (Cuijpers, Jonker, De Weerdt y De Jong 2002). De ahí la conclusión de que el discurso difundido en las campañas es insuficiente, lejano e inadecuado para la desmotivación en el consumo de drogas, debiéndose valorar un cambio en la estrategia preventiva.

Así pues, el objetivo inicial de este trabajo es analizar, por un lado, las razones y demás argumentos que manifiestan los usuarios de drogas para su consumo y, por otro, la respuesta que diseñan y difunden las instituciones públicas, a través de los medios de comunicación, para las campañas de prevención, con el objeto de conocer si éstas son eficaces, o si, por el contrario, refuerzan o al menos dejan indiferentes, tanto a los ya consumidores, como a los usuarios potenciales. En definitiva, con este trabajo se quiere comprobar la necesidad de incorporar un nuevo modelo explicativo, que correlacione dos indicadores de gran relevancia social, a saber: la evolución de las motivaciones para consumir drogas y las campañas de prevención difundidas por la televisión y diseñadas por la Fundación Antidroga (FAD)². Descubrir los efectos psíquicos y sociales del consumo de drogas otorgaría una nueva percepción social de las mismas, a la vez que podría utilizarse para contrarrestar las motivaciones que lo sustentan.

\section{DATOS Y FUENTES}

En la consecución de los objetivos de este trabajo hemos utilizado una serie de fuentes secundarias: para conocer las motivaciones de los consumidores de drogas hemos extraído los datos de los informes bianuales La población andaluza ante las drogas $^{3}$, realizados desde 1987 hasta el 2007. Si bien este informe continúa editándose en el año 2009, las referencias sobre las motivaciones hacia el consumo de drogas han sido eliminadas. El objetivo principal de estas encuestas es conocer la prevalencia del consumo de distintas sustancias psicoactivas entre la población andaluza, así como las principales características sociodemográficas de los consumidores. En cualquier caso, a través de esta fuente se puede comprobar la evolución del tipo de drogas consumidas, así como sus motivaciones, en el transcurso de veinte años en Andalucía.

Esta encuesta recoge tanto datos epidemiológicos, como sociales. Tiene un carácter probabilístico y representativo, con un muestreo estratificado polietápico, por cuotas, atendiendo al género y tamaño del hábitat. Toma como universo la población residente en Andalucía entre 12 y 64 años. La suma de la muestra de estos 20 años asciende a 23.764 individuos $^{4}$.

\footnotetext{
${ }^{2}$ La FAD ha investigado la propia imagen de los jóvenes en los medios de comunicación, a través de un estudio cualitativo, "Los jóvenes en los medios: la imagen mediática de la juventud desde su propia mirada (2007), pero no ha sido correlacionado con las motivaciones en el consumo de drogas.

${ }^{3}$ Hasta el año 2005 el informe se denominaba Los Andaluces ante las Drogas.

${ }^{4}$ El universo lo forma la población andaluza residente en las ocho provincias, aunque la edad considerada para la selección de la muestra ha ido cambiando con el transcurso del tiempo. En los estudios realizados en los años 1987 y 1989 se tuvo en cuenta la población a partir de
} 
Las preguntas formuladas para conocer las motivaciones van dirigidas a aquellas personas que hubieran ingerido alguna vez alcohol, fueran fumadores diarios o hubiesen consumido alguna sustancia ilegal en los últimos seis meses. Concretamente, se les pregunta en qué ambientes o circunstancias comienzan a consumir y por qué motivos. De esta forma, se les pide que señalen las dos razones fundamentales 5 para esos consumos. En relación a las acciones de prevención, hemos analizado las campañas de prevención elaboradas por la FAD, y difundidas por televisión durante el periodo 1988-2007; las cuales contaron con la colaboración desinteresada de la Asociación Española de Agencias de Publicidad, en pro de la elaboración de programas de sensibilización social sobre la problemática de las drogas.

El objetivo principal de estas campañas reside en implantar en la sociedad un cambio de concienciación social que facilite acciones preventivas, sobre todo, en el desarrollo de actitudes positivas y reflexivas para evitar el consumo de drogas. Para establecer la consecución de este fin, hemos analizado las campañas televisadas desde el año 1998 hasta el 2007, principalmente a partir de sus eslóganes; aunque se tienen también en cuenta imágenes y contenidos.

\section{RESULTADOS}

Si bien existen investigaciones que se ocupan de las motivaciones en el consumo de drogas - por ejemplo, la ingesta de éxtasis entre los jóvenes en Asturias, para "divertirse" o "aguantar más tiempo" (Fernández Ludeña y otros 2003: 35) — su descripción se realiza de forma genérica.

De forma pormenorizada, las principales motivaciones para el consumo de drogas se pueden agrupar en cinco grandes grupos: "motivaciones de pasividad y huida", "motivaciones de adaptación e integración", "motivaciones como libertad y trasgresión", "motivaciones sintomatológicas" y "motivaciones experimentales". Cada uno de estos grupos motivacionales encuentra, a su vez, una serie de razones comunes, aludidas de forma espontánea (véase esquema 1).

En general, los resultados de las encuestas muestran que, a lo largo de los años, se produce un drástico descenso del porcentaje de personas que mencionan, como motivación principal para el inicio al consumo, las razones "sintomatológicas" y un incremento de las "experimentales y de placer". Incluso, a partir de 2003, se detecta también una tendencia al incremento de las motivaciones relacionadas con la "libertad y trasgresión".

los 16 años. La encuesta del año 1992 se designó a partir de la población de 14 años en adelante; y en los estudios posteriores (1994, 1996, 1998, 2000 y 2003) la población quedó fijada a partir de 12 años. Como resultado de estas modificaciones y del crecimiento de la población, el tamaño de la población de referencia ha variado.

${ }^{5}$ Sin embargo, debe tenerse en cuenta que una misma persona puede haber consumido varias sustancias psicoactivas, mientras que las razones para el inicio al consumo se pregunta, en general, para cualquiera de las sustancias consumidas; es decir, el entrevistado, al indicar los motivos para iniciarse en el consumo informa para cualquiera de las drogas que haya tomado en los últimos seis meses y no de forma específica para cada una de ellas. Por tanto, los datos ofrecidos solamente son útiles como aproximación para conocer cuáles serían las motivaciones más comunes para el inicio al consumo de cada droga. 
EsQuema 1: Motivaciones para el consumo de drogas 1987-2007.

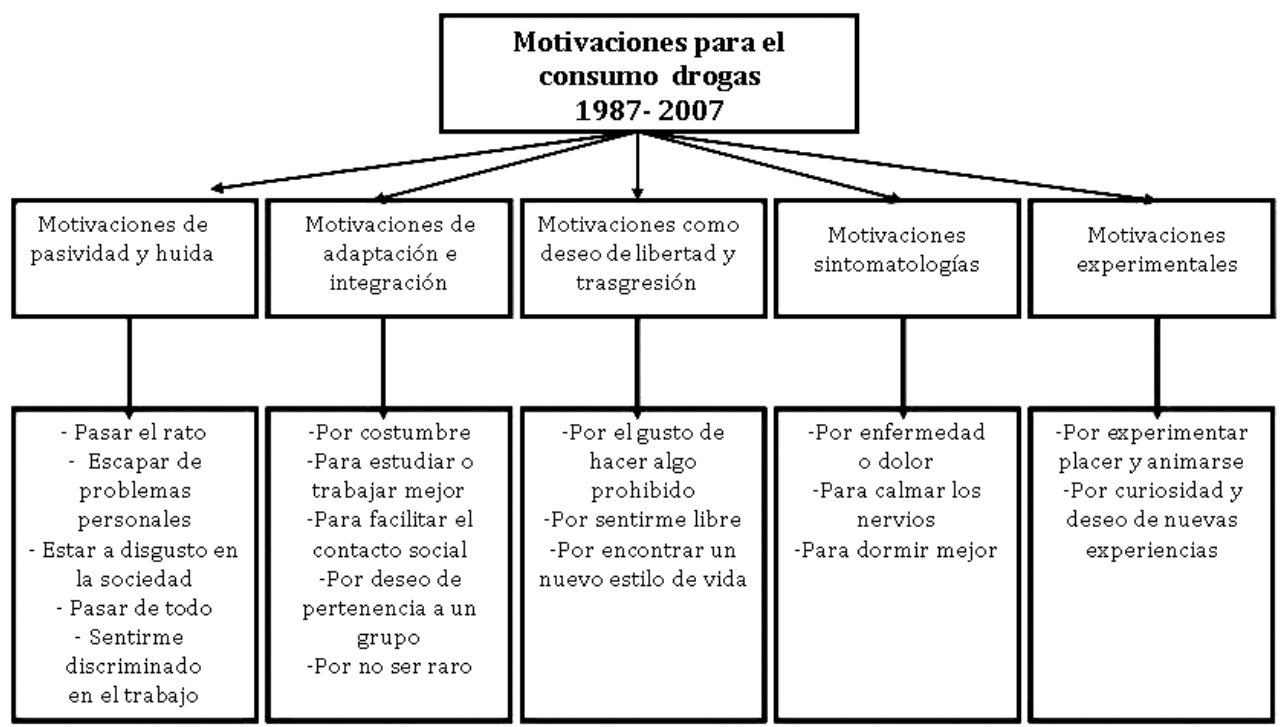

FuENTE: Basado en "Los Andaluces ante las drogas" (1987-2005) y "La población andaluza ante las drogas" (2007). Elaboración propia.

Estas tendencias en la evolución resultan acordes, primero, con el progresivo descenso de la prevalencia de consumo de opiáceos - que podrían relacionarse en mayor medida con las motivaciones "sintomatológicas" ${ }^{6}-\mathrm{y}$, segundo, con el incremento de las llamadas "drogas de la fiesta" o "del baile", como serían la cocaína, el éxtasis y las anfetaminas, que diversos autores relacionarían con una búsqueda controlada de placer y de trasgresión (Duff 2008; Measham 2004; Moore 2008). Más aún, la mención del placer, la experimentación o la búsqueda de libertad y trasgresión son también el reflejo de la aparición de valores sociales emergentes, más permisivos con actitudes hedonistas y de disfrute, propias de las sociedades de consumo desarrolladas (Measham 2004). Por eso, bajo este paradigma de nuevos valores, la búsqueda del placer y de trasgresión se confirma como la motivación promotora del consumo de drogas en la actualidad.

Ahora bien, este cambio motivacional responde a un proceso continuado en el tiempo, pero que, atendiendo a los nuevos tipos de sustancias consumidas y las motivaciones que los sustentan, puede ser dividido en tres grandes etapas. A pesar de ello, las campañas publicitarias cambian solo en lo relativo a las diversas drogas utilizadas y al público objetivo a las que van dirigidas. Veamos esto de manera más detenida.

\footnotetext{
${ }^{6}$ En el año 1987 se cuestionaba en la misma pregunta por las motivaciones para empezar y después continuar el consumo; esta forma de formular la pregunta podría también haber aumentado las menciones de las motivaciones sintomatológicas, que eran muy habituales para la continuación del consumo de opiáceos.
} 
LAS MOTIVACIONES Y LA PUBLICIDAD EN EL PERIODO 1987-1992: LA RESACA DE LA HEROÍNA

Esta primera etapa se caracteriza por un consumo expandido y aceptado de drogas como el tabaco, el alcohol y las drogas-fármaco, y por un crecimiento alarmante de otras drogas, en aquellos momentos, minoritarias, tales como la cocaína o el cannabis; mientras que la heroína se mantendría en un periodo de estabilización, después de haber sido la causa de una enorme alarma social en la primera parte de la década de los 80 .

Las edades de consumo responden a dos perfiles: en primer lugar, los jóvenes que toman inhalables, cannabis, heroína, cocaína y anfetaminas y, en segundo lugar, las drogas de consumo adulto como los tranquilizantes, hipnóticos y analgésicos. Por otro lado, el tabaco y el alcohol son usados por grandes grupos poblacionales, sin distinción de edad.

En relación a las motivaciones para el consumo de drogas en el transcurso del año 1987 al 1992, se observa que aumentaron las de "pasividad y huida", en referencia a criterios como "pasar el rato" o por "costumbre social", frente a las razones que anteriormente se correspondían, de forma mayoritaria, con un consumo paliativo de malestares como el nerviosismo, o la falta de sueño, enmarcadas en las motivaciones "sintomatológicas" (véase gráfico 1).

GRÁFICO 1: Evolución de las motivaciones en los años 1987-1992*.

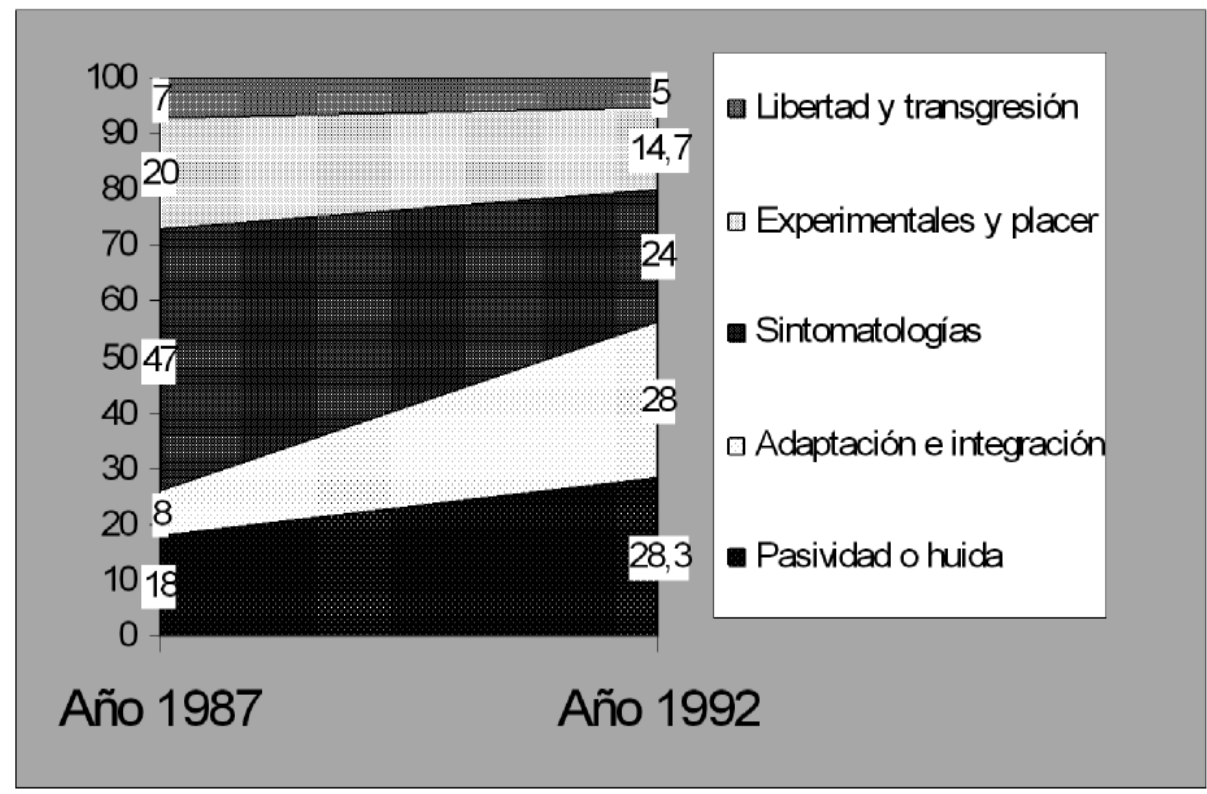

FUENTE: "Los Andaluces ante las drogas" (1987-1992). Elaboración propia.

** En 1989 no se incluyó la pregunta sobre las motivaciones en el informe "Los Andaluces ante las drogas II".

${ }^{7}$ Sin embargo, esto puede ser debido a la inclusión del alcohol en el año 1992 como droga, lo cual contribuyó al incremento de las motivaciones de adaptación e integración. 
En el año 1987, la motivación principal, por tanto, era referida al alivio de diversos síntomas y, en menor medida, a la experimentación, pasividad y huida. Sin embargo, en 1992 las razones "sintomatológicas" quedarían aminoradas frente a motivos de "pasividad y huida", o "adaptación e integración", en sintonía, pues, con las drogas (cocaína, cannabis, alcohol y tabaco) que se utilizaban en diferentes contextos sociales e incluso laborales — como reuniones de trabajo. El progresivo rechazo al consumo de heroína también reflejaría el cambio de actitud en las motivaciones que propiciaron el consumo de otras drogas anteriormente citadas.

En este mismo periodo, las primeras campañas de prevención y concienciación de la FAD intentaron responder a la alarma social que la heroína produjo en el país. Como ejemplos, encontramos la campaña "Engánchate a la vida" (1988) de la agencia "Tandem \& Vitrubio", con un público objetivo de jóvenes de 14 a 25 años. En ella, se pretendía incorporar una alternativa a los soportes tradicionales de los medios de comunicación a través de grafittis, como ejemplo de libre expresión juvenil y participación activa. Posteriormente, se difundiría el uso del lema "Engánchate a la vida" en actos deportivos, musicales, transportes públicos, pegatinas, etc. Con la campaña de "Testimoniales de famosos" (1989), de la agencia "SCACS", se intentó englobar a la sociedad en su conjunto, a través de los testimonios de numerosos artistas y deportistas contra las drogas, utilizados con la intención de obtener una mayor notoriedad en su mensaje. Posteriormente en la campaña "Y tú, ¿qué opinas? I y II" (1990-91)

EsQuema 2: Motivación, droga consumida y campañas de publicidad 1987-1992.

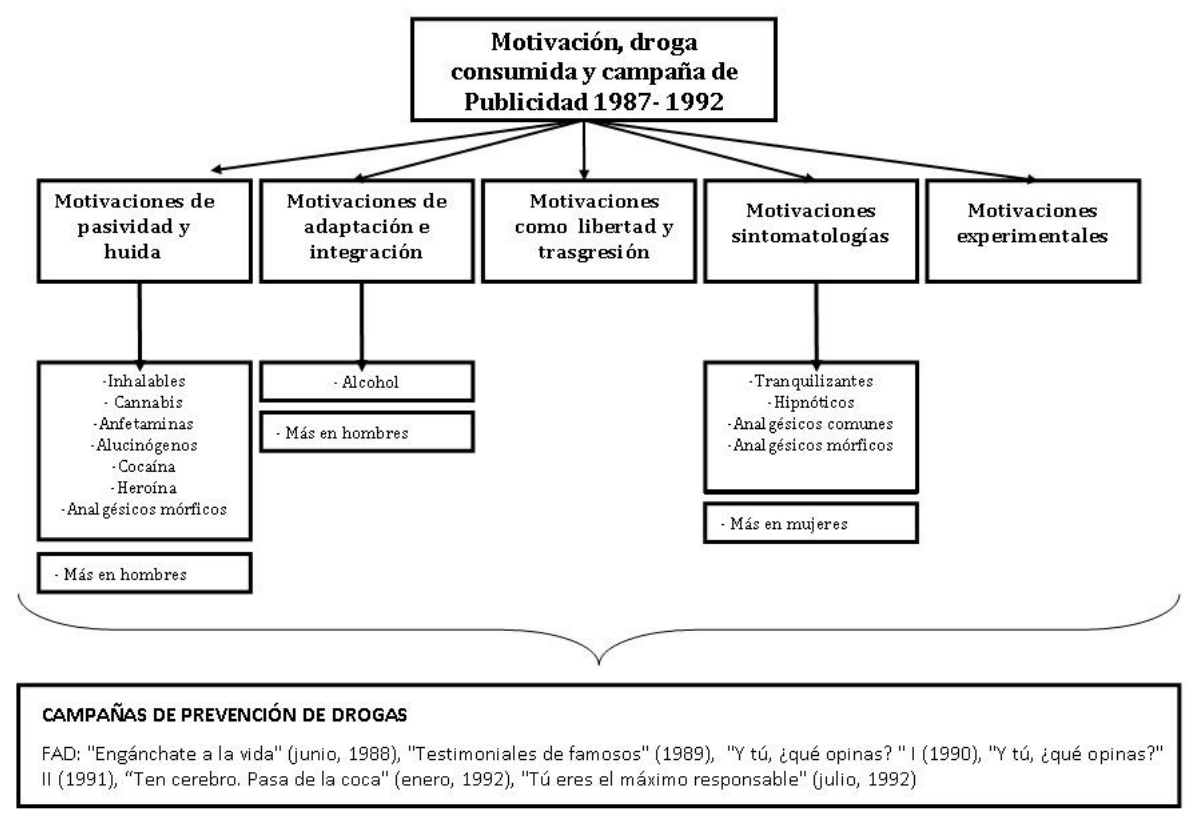

FuENTE: "Los Andaluces ante las drogas" (1987-1992). Elaboración propia. 
de la agencia "J. Walter Thompson", se ejemplificó la opinión de los propios jóvenes a través de otros jóvenes. Se pretendía la implicación del espectador, interpelando al público con la pregunta "Y $Y u$, ¿qué opinas?"

En la siguiente campaña (con similar eslogan) se comenzó a utilizar a actores profesionales, ofreciendo una supuesta mayor creatividad, con mensajes más elaborados y mejores realizaciones formales. El resultado fue una campaña de transición en la que jóvenes actores ofrecían testimonios más concretos y convincentes, en opinión de la propia $\mathrm{FAD}^{8}$.

\section{LAS MOTIVACIONES Y LA PUBLICIDAD EN EL PERIODO 1994-2000: LOS ESTRAGOS DE LA COCAÍNA}

De manera general, en este periodo se produce una regresión en el número de consumidores de heroína y otros opiáceos, así como de tranquilizantes e hipnóticos. Sin embargo, se incrementa el consumo de cannabis, drogas de diseño, alucinógenos y anfetaminas, especialmente en consumidores con un perfil de uso habitual o frecuente. Dentro de las prevalencias más problemáticas, resalta especialmente el consumo de cannabis, anfetaminas, drogas de diseño y cocaína, simultaneado con alcohol y tabaco, dando como resultado final un extendido policonsumo que permanecería todo el periodo (Edis 1994; 1996; 1998; 2000).

Desde el año 1994 hasta el 2000, encontramos que las motivaciones de "huida y pasividad" y "adaptación e integración" se corresponden, consecutivamente, con el consumo de alcohol clasificado tanto como "moderado y excesivo", como "ligero y moderado"s.

Las motivaciones de "libertad y trasgresión" aparecen asociadas al consumo de cocaína, éxtasis, heroína y anfetaminas; mientras que las razones "sintomatológicas" eran causa del consumo de tranquilizantes, hipnóticos y analgésicos comunes y mórficos (especialmente en el caso de las mujeres). En último lugar, las motivaciones alusivas a la búsqueda de placer y experiencias encuentran su razón en el uso de alcohol (en los niveles de clasificación alto, excesivo y de gran riesgo), del cannabis, la cocaína, los alucinógenos y las drogas de síntesis.

Las motivaciones agrupadas que se aluden para consumir estas drogas, recaen, principalmente, en actitudes de "pasividad y huida" y "adaptación e integración". Las razones "experimentales" mantienen su importancia, mientras que las basadas en la "sintomatología" descienden, especialmente, en las mujeres con edades avanzadas y amas de casa (Edis 1994; 1996; 1998; 2000). De manera que los que consumían drogas y alcohol por motivaciones de "libertad y trasgresión", presentarían unas caracte-

\footnotetext{
${ }^{8}$ En http://www.fad.es/Campanas?id_nodo $=3 \&$ accion $=0 \& \&$ keyword=\&auditoria $=F$. Consultado el 26 de junio de 2012.

9 A partir de la conversión de cada bebida en su equivalente de alcohol, y con los datos del consumo de cada entrevistado, se establece una tipología de bebedores según la ingesta de alcohol que, en media diaria, sería la siguiente: abstinentes, ligeros, moderados, altos, excesivos y de gran riesgo. En los hombres se considerará bebedores abusivos a partir de los $75 \mathrm{ml}$. de alcohol al día y para la mujer, siguiendo los criterios internacionales, a partir de los $50 \mathrm{ml}$. Además de en ml. los datos también se pueden estructurar, convertidos en gramos de alcohol y en unidades básicas estándar (UBE) de bebida.
} 
rísticas muy similares a los que lo hacían por cuestiones "experimentales", en ambos casos eran los más jóvenes.

En resumen, se puede decir que las razones de "pasividad y huida" continúan siendo las más comunes entre la población andaluza en estos años. Se produce también, una incipiente disminución en las motivaciones de "adaptación e integración" y se experimenta el mayor descenso en las basadas en la "sintomatología".

GráfICO 2: Evolución de las motivaciones en los años 1994-2000.

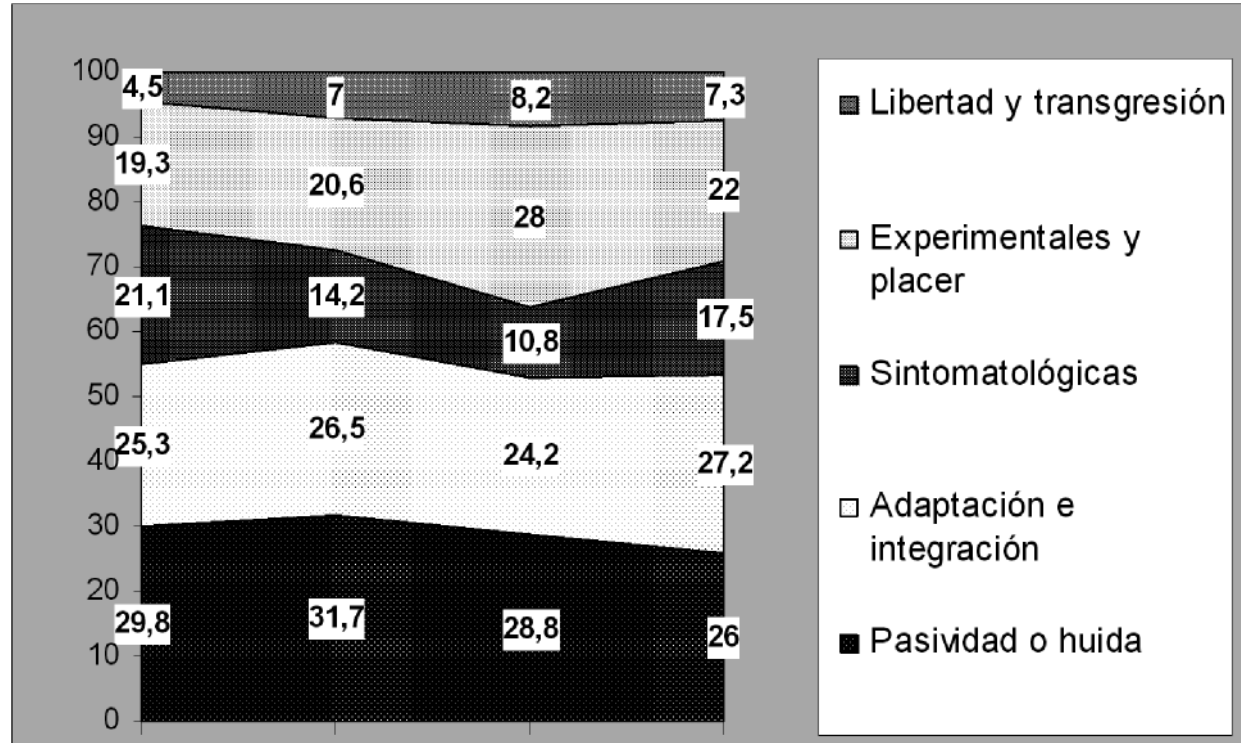

\section{Año 1994 Año 1996 Año 1998 Año 2000}

FUENTE: “Los Andaluces ante las drogas" (1994-96-98-00). Elaboración propia.

En cuanto a las campañas de publicidad difundidas como medida de prevención en la FAD aparecen: "Ten cerebro. Pasa de la coca" (1992) de "Saatchi \& Saatchi" con un público objetivo generalizado, donde se pretendió mediante imágenes impactantes, alertar del riesgo del consumo prolongado de cocaína. Con el lema "Tú eres el máximo responsable" (1992), "Gallina. Atrévete. Di NO" (1993/94) y "Hay un montón de razones para decir NO" (1995) la agencia "Lintas" increpaba a los jóvenes a rechazar enérgicamente, tanto la compra, como el consumo de drogas. Posteriormente, incluso enunciarían todas "las cosas" maravillosas (estas cosas serían Bart Simpson, mi amiga, el campo, mi perro, las gominolas, hablar por teléfono, mi vecina, Winona Ryder, la Pfeiffer, los amigos, las pizzas,...) que impedirían el consumo de drogas. Tendríamos por tanto, el di "NO" a las drogas, frente al di "SI" a otras "Cosas". Con "Habla con tu bijo" (1995), la agencia "Tiempo / BBDO" intentaba impulsar la necesidad de comunicación entre padres e hijos, recordando a los padres su responsabilidad de ayudar al desarrollo vital de sus hijos. De esta misma agencia, la campaña "Control" (1996) era dirigida a los jóvenes, con la inten- 
ción de desmitificar la idea de que era posible controlar las drogas. Con un lenguaje proveniente del argot juvenil, asemejaban el control con actividades deportivas que requieren dominio y equilibrio (deportes de riesgo como escalada o esquí acuático). La percepción de las "nuevas drogas" como "más controlables" argumentaba el contenido de esta campaña, que reforzaría el peligro de las drogas, pretendiendo desmitificar el "yo controlo". En "Prevenir es vivir" I y II (1997/98), la agencia "Vitrubio / Leo Burnett" intentaba captar la atención de padres, madres y adolescentes a través de la incorporación de una nueva perspectiva; la prevención ante todo. En "Las drogas no son un juego" I y II (1998), esta misma agencia incitó a los jóvenes a reflexionar sobre el sentido lúdico de las drogas, remarcando la gravedad de estos consumos. Con el lema "Y tú, ¿cómo lo ves?" y "Drogas. Mejor sin ellas" I y II (2000/01) la agencia "SCPF" mostraba a los jóvenes las consecuencias del consumo de drogas en diversas circunstancias cotidianas, y en la campaña "Libre" (2000) se anima a la reflexión sobre hasta que punto somos libres para optar por el uso de drogas.

Esquema 3: Motivación, droga consumida y campañas de publicidad 1994-2000

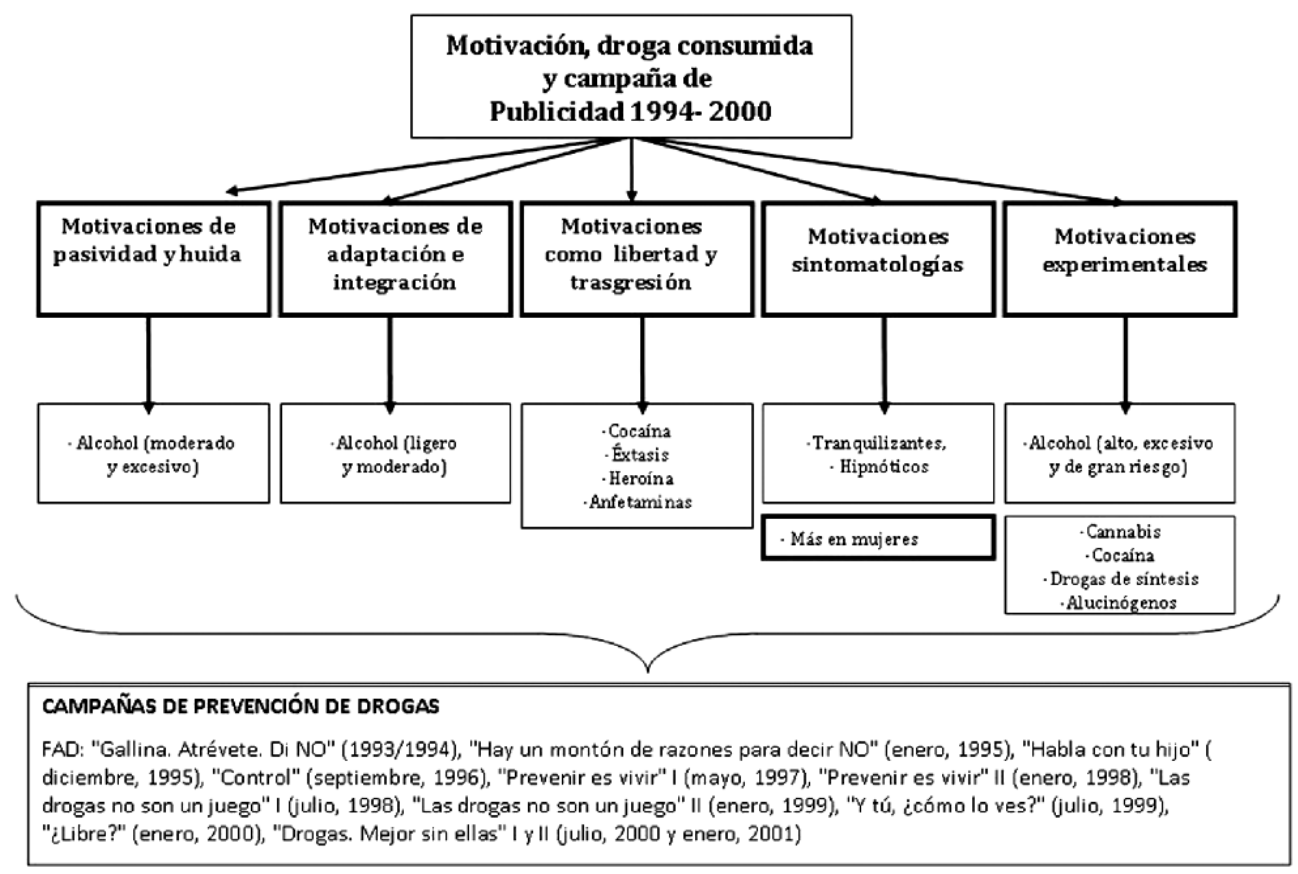

FUENTE: “Los Andaluces ante las drogas”(1994-1996-1998 y 2000). Elaboración propia

LAS MOTIVACIONES Y LA PUBLICIDAD EN EL PERIODO 2003-2007: QUE NO PARE LA FIESTA

Desde el año 2003 hasta el 2005, las drogas con un uso relativamente amplio, tras el tabaco y el alcohol, serían el cannabis, los tranquilizantes, los hipnóticos y la co- 
caína. Para el resto de sustancias el consumo sería más minoritario, oscilando entre el éxtasis, e incluso el crack. Los hombres tendrían índices más altos en tabaco y alcohol de manera abusiva, al igual que en inhalables, cannabis, cocaína, éxtasis, alucinógenos y el crack. Por su parte, las mujeres tendían más a consumir anfetaminas, tranquilizantes, hipnóticos y analgésicos opiáceos (Edis 2003). Sin embargo, en el año 2007, el consumo seguía siendo mayoritario de tabaco y alcohol, pero las drogas no legalizadas con un uso más extendido en la población andaluza fueron el cannabis y la cocaína en polvo. El éxtasis y los alucinógenos presentaron, también, prevalencias relativamente altas. El consumo ocasional de cocaína en polvo, de éxtasis y de alucinógenos se habría incrementado con respecto al 2005; los consumos más recientes (último mes) de estas sustancias se mantienen más estables (Edis 2007). En este último año, asistimos a la emergencia de un nuevo patrón de policonsumo, caracterizado principalmente por ser consumos recreativos en ámbitos y circunstancias festivas (raves), por una población de jóvenes inmersos en un entramado de ofertas festivas con varios días de duración.

Las motivaciones, a partir del año 2003, cambiaron de forma drástica. La variación más acusada se produjo en dos tipos: las "experimentales y placer", que se convirtieron en la razón principal para el uso de drogas, y en las "sintomatológicas" que descendieron en el orden de importancia hasta el último lugar (recordamos que en 1987 era la motivación cardinal en el consumo de drogas). A estos motivos, les siguieron las razones de "adaptación e integración" que también disminuyeron; las de "libertad y trasgresión" que se incrementaron; y las de "pasividad y huida" que fueron las más estables en el tiempo. Por tanto, el consumo de drogas estuvo motivado por la "pasividad y huida", como respuesta a situaciones problemáticas o frustrantes, y por la "experimentación-placer" y "libertad-trasgresión", como respuesta a una actitud hedonista. Hasta el punto de que estos tres tipos de razones acumulan la amplia mayoría de las respuestas.

En relación a las sustancias, se observa como en el consumo de alcohol imperan las motivaciones "adaptación- integración" y "pasividad y huida" (ligeros y moderados), y "experimentar placer" (abusivos). En otras drogas se imponen las motivaciones "experimentales-placer", como son el caso de inhalables, cannabis, cocaína, éxtasis y alucinógenos. Para la heroína, la motivación principal fue la huida; y en los tranquilizantes, hipnóticos, y demás opiáceos, se aludieron cuestiones sintomatológicas.

En el año 2002, se complementa la investigación del consumo de drogas de los andaluces con un informe específico sobre la juventud. En este informe se expone como los jóvenes ansiaban en sus consumos primero la experimentación de sensaciones nuevas y placenteras; en segundo lugar, alegaban motivaciones de pasividad y huída; y en tercer lugar, las razones hacían referencia a la trasgresión y libertad. En 2005 y 2007 se ratificarían las motivaciones "experimentales", de "adaptación e integración" y de "pasividad y huida", acumulando un $79,7 \%$ del total de respuestas. Las "sintomatológicas" y las de "libertad y trasgresión" (6,7\% y 13,6\%, respectivamente) acumulan el 20,3\% restante (véase gráfico 3).

En estos años, se televisarían las campañas de la FAD: "Haz algo" (2001) de la agencia "Contrapunto", que pretendía difundir que el consumo de droga afecta tanto a los usuarios como a su entorno familiar y se avisaba de la existencia de un teléfono al cual dirigirse ante la necesidad de información. De la misma agencia, la cam- 
paña "La educación lo es todo" (2002) y "En pañales ante las drogas" (2002) se asentaba en la creencia de que existe una clara interrelación entre los consumos de drogas y otros conflictos más genéricos. Por este motivo, la FAD afirmaba que era imprescindible la educación preventiva con objeto de conseguir una formación integral que prepare la personalidad del niño para cualquier riesgo de conducta antisocial. Sin una educación integral adecuada desde los primeros años, los jóvenes estarían indefensos ante las drogas, o sea "en pañales".

GRÁFICO 3: Evolución de las motivaciones en los años 2003-2007.

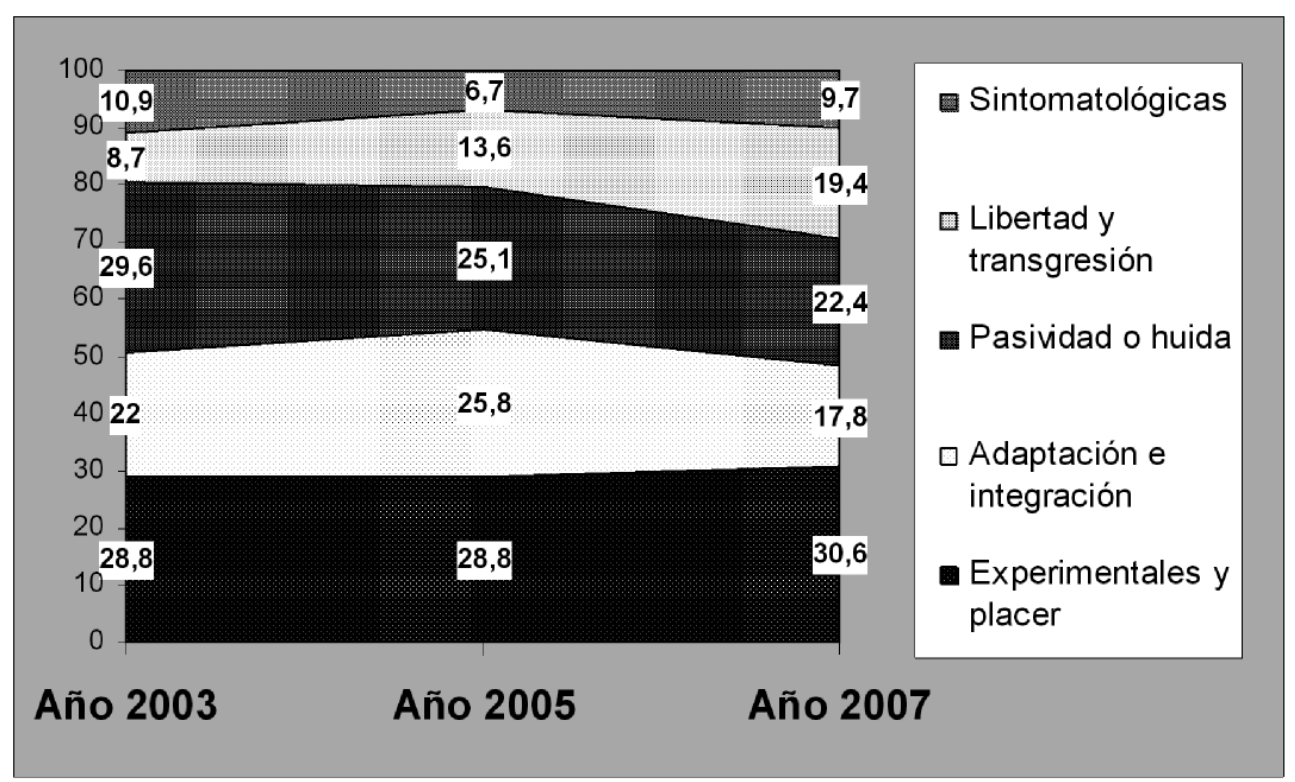

FUENTE: "Los Andaluces ante las drogas"(2003-05-07). Elaboración propia.

Con "Todos somos responsables" (2003), esta misma filosofía se expandiría a publicitarios, padres/madres, educadores, medios de comunicación, músicos, deportistas, etc. Posteriormente, esta misma agencia, diseñó la campaña "No sabes lo que te metes" (2003), con el objetivo de prevenir el aumento en los consumos de drogas de síntesis y cocaína durante la época estival, y alertar sobre el uso lúdico de estas sustancias, apelando a la responsabilidad de los consumidores, especialmente jóvenes de 14 a 25 años.

La agencia publicitaria "La Banda Arnold" insistió de nuevo en la educación que deben llevar a cabo los padres, las madres y los propios educadores en "Enséñales a vivir" (2004). Con "Ten cerebro, pasa de la coca" (2004), "Saatchi \& Saatchi" diseñó una campaña para prevenir los consumos de cocaína de los jóvenes, especialmente durante las vacaciones de verano. En la campaña "Da poder a tus bijos frente a las drogas" (2004), la agencia "Arnold Spain" insistió a los padres y madres en la importancia de la educación en valores y la promoción de la actitud crítica como factor de protección y prevención de los riesgos relacionados con los consumos de drogas. 
Asimismo, en "Cada vez cuenta. Piensa" I y II (2005), "Será ésta? Piensa" (2006), "Las drogas deciden cuando te va cambiar la vida" (2006) y "Cambia tu percepción. Pien$s a$ " (2007), la agencia "Delvico Red Cell" alertó de los peligros de las drogas, intentando incidir en la falsedad de la sensación de control que muchos de los consumidores jóvenes sienten con respecto al uso que realizan de las drogas, insistiendo en los problemas que estos consumos suponen para la sociedad en general. En último lugar, la campaña "Todo tiene un precio" de la agencia "Sra. Rushmore" mostró una perspectiva de la presencia cultural de las drogas como un producto de consumo más, banalizando su significado y sus riesgos. El concepto creativo de la nueva campaña se apoya en la afirmación "Lo más peligroso de las drogas es olvidarnos de lo que realmente son".

EsQuema 4: Motivación, droga consumida y campañas de publicidad 2003-2007

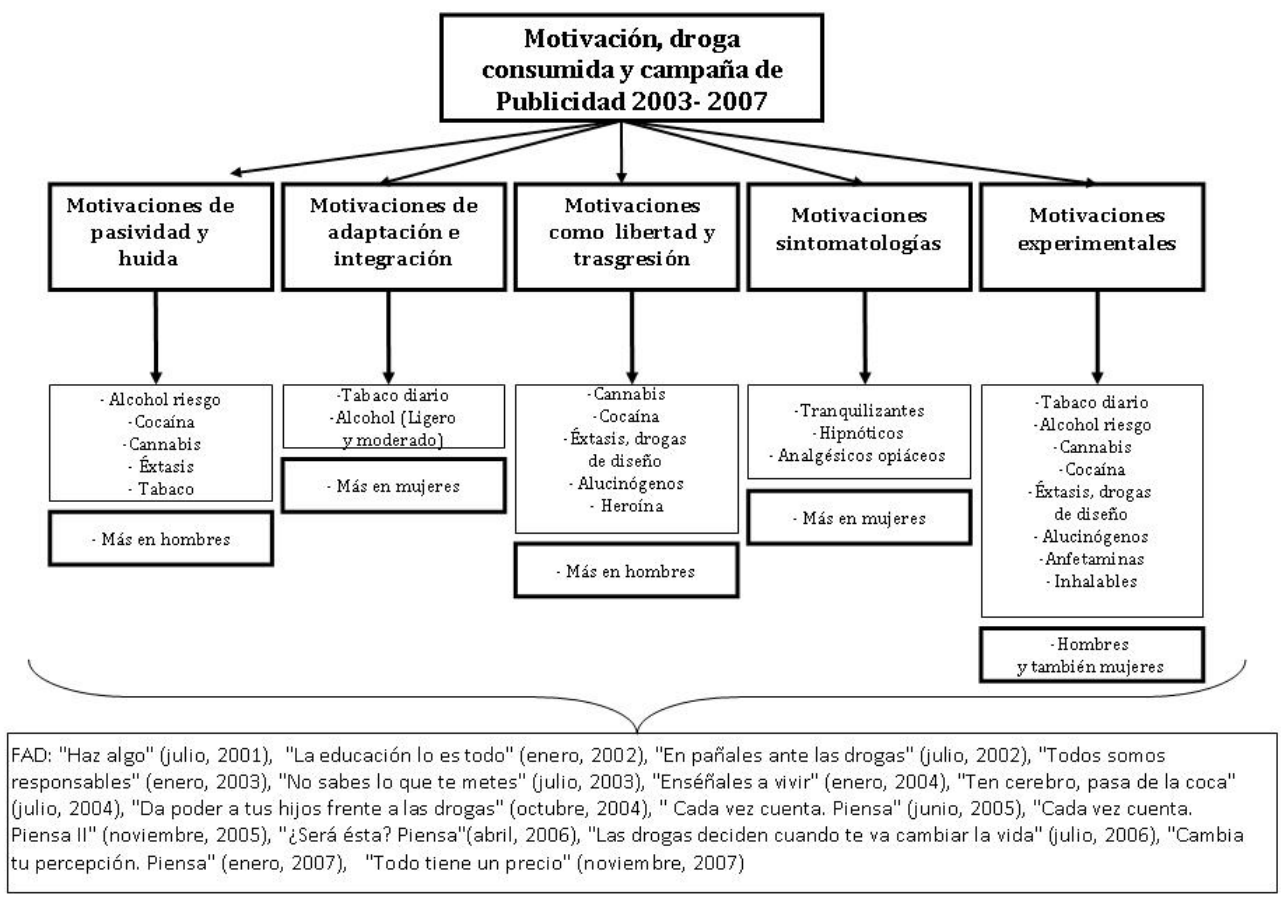

FUENTE: "Los Andaluces ante las drogas" (2003-05-07). Elaboración propia.

\section{DISCUSIÓN}

Las campañas de publicidad en el periodo estudiado, comenzarían con la difusión de mensajes como el "Engánchate a la vida" (1988), donde se incitaba a los jóvenes a que "pintaran" su propia vida, en una clara alusión a la decisión individual de no consumir drogas. Ciertamente, el mensaje se orientaba hacia la negación y defensa ante la manipulación que condicionaba el consumo de drogas. Sin embargo, lo cier- 
to es que si las motivaciones que aludían los consumidores de drogas eran principalmente sintomatológicas o integradoras, el mensaje de la manipulación aparecía como ajeno a la realidad del usuario de drogas. Más aún, con la campaña testimonial de famosos (1989), y con el tema musical "engánchate a la vida", se dio, lamentablemente, una de las situaciones más cínicas e irónicas de la historia de las campañas de prevención, ya que algunos de estos personajes famosos consumían drogas de forma evidente y, sin embargo, eran capaces de aparecer desaconsejando su uso ${ }^{10}$. De ahí que la realidad del consumo de drogas se mostrara muy distante del sentido de las campañas de prevención televisivas. Las motivaciones que influían en el consumo de drogas en estos primeros años hacían referencia a razones "sintomatológicas" y "experimentales", aunque las campañas continuarían difundiendo un discurso centrado en el consumo de drogas por manipulación, lo cual era poco acertado y nada realista.

Con posterioridad surgieron las campañas "Y tú, ¿qué opinas? I y II" (1990 y 1991), donde una serie de jóvenes hablaban de las drogas, en un intento por captar la atención de otros jóvenes a través de mensajes como "la droga te deja en pelotas" o "la droga te quita las ideas". Estos anuncios tratarían de imitar el lenguaje de los jóvenes para conseguir que el mensaje fuera más cercano y familiar a este colectivo. No obstante, en la mayoría de las ocasiones, estas campañas propiciaron un desconcierto aún mayor, ya que las drogas eran atractivas en el imaginario de los jóvenes, y los adultos sólo intentaban inmiscuirse en sus asuntos, haciéndose pasar de forma ridícula por uno de ellos. Podríamos afirmar incluso, que los jóvenes no se sentían identificados con estas campañas, y que los fatuos intentos de acceder al mundo de los jóvenes "de una forma joven", era una estrategia bastante penosa y poco convincente. Tal vez la mejor manera de que los jóvenes se comporten como adultos responsables sería tratarlos y dirigirse a ellos como adultos responsables.

Insistimos, también, en que estas campañas propiciaron la difusión de un mensaje que describía a las drogas como un ente cuyo poder anulaba al individuo, lo cual también se mostraba de manera inadecuada, tanto por el tipo de drogas que emergían -basta con recordar el drástico descenso de consumo de heroína y el principio de la expansión de la cocaína-, como la manipulación, puesto que no era una de las razones que se aludiría para el consumo de drogas: "me drogo porque he sido manipulado o engañado". La opinión de los que creen que los jóvenes son manipulados de forma sencilla, supone dejar a los jóvenes consumidores de drogas sin poder decisorio sobre sus actos, en un alarde de falta de potestad, criterio y responsabilidad personal. Basta que trates como niños a los jóvenes, para que se comporten como tales; justo lo contrario de lo que debería de ser el mensaje preventivo en el uso de drogas.

Se entiende, por tanto, que un mensaje más realista sobre el consumo de drogas, donde ese poder manipulador magnificado fuera descartado, dejaría espacio a otro tipo de interpretaciones más coherentes con las motivaciones para su uso. Incluso, la afirmación sencilla de que, en la mayoría de los casos, las drogas no son unas sus-

\footnotetext{
${ }^{10}$ Por ejemplo, en una entrevista, publicada en El Gran Musical, E. Urquijo (fallecido por sobredosis) decía "es como aquello de los conciertos contra la droga, que salían todos superpuestos" http://enriqueurquijo.foro-libre.com/t799-entrevista-a-enrique-en-el-gran-musical-octubre1991. Consultado el 20 de junio de 2012.
} 
tancias tan poderosas, sino que sus consumos podrían ser calificados de decepcionantes e incluso absurdos. Más ejemplos de esta magnificación de las drogas se encuentran en las mismas campañas, donde la gente joven hablaba de cómo con las drogas "no te enteras de la diversión", cuando lo cierto sería que, en multitud de ocasiones, las drogas, llanamente, no son divertidas.

En el año 1992, la campaña televisiva "ten cerebro, pasa de la coca mostraría un gusano reptando por la nariz hacia el cerebro, imagen impactante y certera, que contribuiría al esclarecimiento y reflexión sobre el consumo de cocaína. Ese mismo año, la campaña de prevención "tú eres el máximo responsable", incorporó la célebre frase "di NO"; otorgando la potestad de los actos a la propia persona. De esta forma, se olvidaría el engaño y la manipulación como los culpables del consumo de drogas. Las motivaciones principales en 1992 eran de "pasividad o huida" y "adaptación e integración", así que cuando se responsabilizó al propio individuo de sus actos, se avanzó hacia una estrategia efectiva de prevención del consumo, pero se obvió que las drogas, especialmente el alcohol (de forma abusiva) y la cocaína, pueden ser adaptativas e integradoras, pero también podrían proporcionar las escenas más bochornosas de los consumidores, provocando similar rechazo. Tan sencillo como que si las personas buscan la aceptación e integración en el grupo a través del consumo de drogas, ese consumo también puede tener el efecto contrario, llevar al ridículo y ser, por tanto, excluido. Por eso, se trata de desmotivar el consumo de drogas a través de las motivaciones que lo propician.

También las motivaciones de "huida o pasividad" son irreales para ciertas drogas (excepto las que confieren un efecto concreto de inconsciencia, como los opiáceos o fármacos mórficos). Más aún, el sentido que se les confiere a ciertas drogas, es el contrario al efecto que se obtiene de ellas, lo cual podría ser una premisa básica en la desmotivación de su uso.

Las campañas de prevención a partir de 1993/94 presentaron la misma tendencia que en el periodo anterior; puesto que en ellas se señaló que la responsabilidad y la capacidad decisoria recaía, exclusivamente, sobre los propios individuos, en un intento por defender una postura digna y valiente a través del "di NO". De esta forma, la protagonista es una chica que "pasaba" del camello. Sin embargo, una vez asentada la postura del "di $N O$ ", las siguientes campañas intentarían vanamente convencer de por qué habría que negarse a consumir drogas. En "Hay un montón de razones para decir NO" (1995), se incitaba a apreciar y valorar una serie de personalidades, situaciones y "Cosas" (recordamos; mi perro, hablar por teléfono, el fútbol, Winona Ryder, etc.). Sin embargo, de estas campañas se extraen varias conclusiones: en primer lugar, que las drogas, en los primeros estadios de consumo, tienen una parcela de poder bien definida, donde no interfieren con otras situaciones y circunstancias (se puede hablar por teléfono y ver el fútbol de forma simultánea al consumo de drogas) y, en segundo lugar, que las drogas no se consumen para dejar de tener un perro, o para que te dejen de gustar los actores y actrices famosos; con lo cual, insistimos, el consumo de drogas debe verse motivado por una serie de aspiraciones complementarias a cualquiera de las razones aludidas en el "di NO. De manera que si las drogas venían motivadas por el aburrimiento o la insatisfacción, lo más oportuno habría sido aclarar cómo el consumo de drogas puede llegar a ser tedioso y cansino, falto de sentido y extremadamente frustrante. Las drogas, pues, no reportan una sali- 
da satisfactoria a estas circunstancias, sino que, en la mayoría de las ocasiones, son un gasto de dinero, salud y seguridad, ejemplificado en un joven perdido y ridículo.

Las posteriores campañas expusieron el necesario diálogo de padres e hijos para prevenir el uso de drogas en "habla con tu bijo" (1995), "Prevenir es vivir" I y II (1997, 1998) y "Las drogas no son un juego" I y II (1998, 1999). Estas campañas intentaron establecer una corresponsabilidad en la prevención del consumo de drogas a través de la familia. Sin embargo, en la mayoría de las ocasiones, la prevención recae más en los grupos de pares o en los propios medios de comunicación, siendo para los padres una esfera privada e inaccesible de la vida de sus hijos.

En 1996 también se desmitificó el consabido "yo controlo" a través de la campaña "Control" (1996); aunque ninguna de las razones que se exponían en relación al consumo de drogas en estos años tuvieron ese motivo sustentador "consumo drogas porque soy capaz de controlarlas". Basta recordar que las motivaciones de estos años recaían en actitudes de pasividad e inercia, justamente lo opuesto a razones de un exceso de seguridad en sí mismo, que permitiera "controlar las drogas".

En la campaña "¿Libre?" (2000) se metaforizaba el consumo de drogas con una mosca que chocaba constantemente contra un cristal, que le impedía salir al exterior. De esta forma, se instaba a los consumidores a entender que el uso de drogas puede dejar de ser una decisión individual, para convertirse en una necesidad. Con todo, las consecuencias de la adicción se muestran evidentes e importantes, pero no suficientes para esgrimir un discurso desmotivador al consumo eventual o, por lo menos, en sus primeras fases.

En las siguientes campañas televisadas "Drogas. Mejor sin ellas" I y II (2000, 2001) se insistió en aclarar los peores efectos de diferentes sustancias (alcohol, cocaína, hachís y pastillas) sobre distintos jóvenes en situaciones cotidianas, lo cual muestra un cambio de orientación en la perspectiva del consumo de drogas, porque la cocaína, el alcohol, el cannabis, y las drogas de diseño implicarían una serie de efectos, que en casi todos los casos, acarrean resultados no deseados o agradables. Por primera vez, se habla de los efectos reales de las drogas, dejando a un lado las implicaciones sociales o la negación de las drogas desde una perspectiva tendenciosa y reduccionista.

En las campañas posteriores se expuso la educación y la información como criterio principal de defensa ante el consumo de drogas. En "Haz algo" (2001), donde aparecían imágenes de adultos (padres) con un obvio consumo de drogas, difundiendo mensajes del tipo "Nadie nace cocainómano" o "La educación lo es todo" (2002); e incluso, representando a los consumidores como unos "bebés" desprovistos de capacidad y habilidades de defensa: "en pañales ante las drogas" (2002). Evidentemente, estos mensajes no tienen ninguna correlación con la búsqueda de sensaciones de los consumidores de drogas, ni con el placer que se atribuyen a ciertas sustancias, ni con la satisfacción de saltarse las normas convencionales. Tal vez, una mayor atención de los adultos podría conllevar una posibilidad de reducir el consumo de drogas, sin ignorar que estaríamos ante un estado de vigilancia y control, lo cual queda lejos de mostrarse como un impedimento real y podría convertirse, inmediatamente, en un incentivo al que superar por parte de los jóvenes consumidores de drogas.

La campaña "Todos somos responsables" (2003) amplió su horizonte de atención sobre el fenómeno de las drogas, incluyendo a múltiples y diversos agentes sociales, ya que la responsabilidad de la prevención debía recaer en los medios de comunica- 
ción, padres y educadores. Con frases lapidarias como "si tienes el poder de hacerles creer que con unos vaqueros atraviesas paredes, imaginate el poder que tienes", exponían que la venta de sueños en la publicidad no debía ser partícipe de una concepción de las drogas irreal y peligrosa. En los años siguientes se seguirá exprimiendo la postura de prevención basada en la educación, en las campañas "Enséñales a vivir" I y II (2004, 2009), "Ten cerebro, pasa de la coca" (2004) y "Da poder a tus hijos frente a las drogas" (2004), pero, en cualquier caso, se sigue sin promover la desmotivación de los consumidores de drogas.

Otra estrategia preventiva desarrollada en ese mismo año afirmaba: "No sabes lo que te metes" (2003). De esta forma, se daba cuenta del descontrol y falta de fiabilidad en la composición de las sustancias psicoactivas, en un alarde de mostrar el peligro que supone la adulteración de las drogas. Así pues, los efectos de ciertas sustancias en su estado no adulterado serían desconocidos, en comparación con la realidad de lo que se compra en el mercado negro. Cuando la población alude al placer como motivo para consumir drogas se hace preciso aclarar que éste podría encontrarse en la sustancia primigenia, pero no en la drogas que se adulteran en cada eslabón de la cadena del menudeo.

Por otra parte, las campañas de la FAD, como "Cada vez cuenta. Piensa" I (2005), "¿Será ésta? Piensa" II (2006), "Las drogas deciden cuando te va cambiar la vida" (2006), "Cambia tu percepción. Piensa" (2007) y "Todo tiene un precio" (2007), abogaron por una comprensión del problema de las drogas en relación directa a las consecuencias peligrosas de su consumo. Se trataba de mensajes que evidenciaban la ingenuidad y falsedad de los argumentos sobre el consumo de drogas, en los que su uso puede aparecer como inocuo y sin riesgos, simplemente motivado por la diversión. Sin embargo, si el peligro de las drogas es evidente, también lo sería explicar que las drogas no sólo no son divertidas, en muchas ocasiones, sino que son generadoras y proclives a la creación de múltiples estados dolorosos, ansiosos e incluso tediosos. De manera que el coste-beneficio de esta búsqueda de la diversión, en multitud de ocasiones, es contrario a lo esperado. Incluso más, el coste emocional, físico, social y económico que conlleva el consumo de drogas resulta insultante para el beneficio que se obtiene, donde la buscada recreación se transforma, la mayoría de las veces, en un periplo infructuoso del cual arrepentirse. En ninguna de estas campañas se expone o resalta que el consumo no lleva irremediablemente al ansiado placer o la diversión. El displacer que conlleva el consumo de ciertas drogas es tan real y verídico, como el placer que se puede obtener en algunas ocasiones. Se trata, por tanto, de aclarar que ambas sensaciones forman parte del mismo hecho, en un intento por desilusionar, desmitificar y desmotivar el consumo de drogas, especialmente en las poblaciones más jóvenes.

Podemos encontrar diversos estudios que ejemplifican el fracaso de las campañas de prevención. Por ejemplo, encontramos grandes contradicciones ejemplificadas en cómo los mayores de 21 años, residentes en barrios con problemáticas de drogadicciones asociadas, aún siendo conscientes de las campañas dictadas contra el consumo de sustancias psicoactivas no legalizadas, aumentaban su consumo de estas drogas (Kadushin, Beveridge y Livert 1997). Incluso entre los jóvenes existía la creencia de que prohibir determinadas drogas incrementaría el deseo de consumo de las mismas. Los escolares, por tanto, veían el hecho de la prohibición de su consumo como 
un aliciente, aunque entre las motivaciones manifestadas por esta población, prevalecen las de carácter lúdico o experimentación frente a la trasgresión (Calafat 2003).

Existen estudios que concluyen que los consumidores frecuentes de drogas aceptan positivamente los mensajes permisivos sobre el consumo y los consejos para prevenir consecuencias adversas (reducción de daño), y que los no consumidores prefieren los mensajes punitivos (Amigó 1997). Estos resultados pueden esclarecer el fracaso de los programas de prevención del consumo de drogas y de la actual política prohibicionista de la lucha contra la droga, expresando alternativas en ambos aspectos.

Los consumidores de drogas, lo hacen incentivados por el deseo de mejorar la experiencia vital y porque tienden a infravalorar las consecuencias negativas del consumo y los riesgos que conlleva (Aitken, Crofts y Kerger 2000). Por eso, puede resultar enormemente beneficioso ser más explícito en las campañas de prevención, en relación a la falta de consecución de los efectos ansiados, frente a la probabilidad de padecer los riesgos asociados.

Algunos autores, como Bobes y Sáiz (2003), sostienen que los no consumidores de drogas piensan que los usuarios de las mismas lo hacen porque no tienen interés en sí mismos, que esto es propio de vidas "sin sentido" y que empeora la situación de la comunidad global. Inversamente, los usuarios argumentan que no se consumen drogas por el desconocimiento de sus efectos y "por miedo a efectos negativos del consumo". Con lo cual, la población no consumidora ejemplifica a los consumidores a través de estereotipos basados en perfiles muy característicos "vidas sin sentido, manipulados, perniciosos para la sociedad"; una imagen a la que se ha contribuido desde los propios medios de comunicación, especialmente en las campañas de prevención. Sin embargo, los que sí consumen, aluden a que los no usuarios de drogas, no lo hacen porque están "desinformados, asustados"; o sea, que se han creído los mensajes de las campañas de prevención. Esto nos lleva a dos reflexiones: primera, ninguna de las dos posturas es realista, sino que ambas responden a estereotipos mediatizados, y segunda, la prevención de drogas no implica a los que las usan, puesto que no hablan de lo que significa realmente consumir drogas, ni de las motivaciones que mantienen esos consumos. Con lo cual, se previene a los que no consumen, mientras que los que sí consumen permanecen inmutables. Y sin embargo, el número de consumidores continúa en aumento. Con lo cual, ni siquiera se previene.

No obstante, y a pesar de esa clara evidencia, la propia FAD sostiene la eficacia

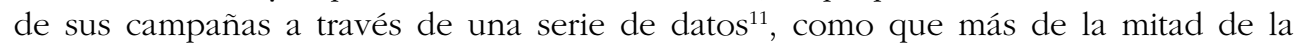
población española de 15 a 65 años indica que conoce o ha oído hablar en alguna ocasión de la FAD, o que el 90,5\% del total de los entrevistados conoce alguna o algunas de las imágenes de sus campañas. Insisten en que un amplísimo segmento de la población española de 15 a 65 años (91,7\%) considera que las campañas son importantes o muy importantes, e incluso, que también es muy alta la proporción de los que creen que es importante la continuidad de las mismas $(89,5 \%)$. Lo cual significa que el reconocimiento de las campañas de prevención es suficiente para que sean un éxito. No estamos haciendo referencia a que las campañas de prevención hayan conseguido descender o aminorar las prevalencias y el número de consumidores de

\footnotetext{
${ }^{11}$ En http://www.fad.es/dossieres/CampanasFAD.pdf. Consultado el 20 de mayo de 2012.
} 
drogas, sino que nos contentamos con la sencilla cuestión de si se ve la televisión (y por lo tanto, los anuncios de la FAD).

\section{CONCLUSIONES}

Las motivaciones que propician el consumo de drogas por algunos sectores de la población están regidas por una serie de expectativas acerca de los efectos de estas sustancias. Además, esas "ganancias" coexisten con unas creencias compartidas sobre la presencia o ausencia de riesgos asociados y con diversas actitudes consensuadas, tanto en los grupos de pares como en el entorno social cercano, a favor del consumo de drogas.

El análisis de los contenidos de las campañas de prevención del consumo de drogas, difundidas por los medios de comunicación, especialmente en la televisión, por parte de la FAD, nos ha permitido comprobar que estas campañas difícilmente contrarrestan el consumo de drogas, al no ser coherentes con las motivaciones aludidas por los usuarios de las mismas, en cualquiera de las etapas cronológicas reflejadas. Hasta el punto de que si las drogas mantienen una posición de poder en el imaginario colectivo, las campañas se sustentan en una serie de discursos amparados en el miedo, alarmismo y la falta de criterios verídicos que los alejan de sus objetivos de prevención (especialmente relevante resultan los inicios de la difusión de estas primeras campañas). Por tanto, el discurso esgrimido desde las instituciones, no responde ni contrarresta las motivaciones que llevan a las personas a usar y abusar de las diferentes drogas.

La falta de éxito de las campañas publicitarias en contra del consumo de drogas, nos lleva a pensar que se precisa de una nueva postura teórica comunicativa hacia las drogas, la cual debería olvidar, en parte, los mensajes de dramatismo y victimismo social, para centrarse en un discurso basado en la cara inversa del consumo; esto es, si las drogas producen placer, también generan amplias dosis de displacer; si con ellas se consiguen experiencias nuevas y placenteras, mayores son las desagradables; si causan euforia también tristeza; aunque ofrezcan sociabilidad, pueden generan gran aislamiento social, etc. Revertir la imagen del consumo de drogas, en relación directa a las motivaciones que propician su uso, se convierte pues, en una opción y en una posibilidad a tener en cuenta. Como ejemplo de esta nueva perspectiva en la prevención del consumo de drogas y campañas de reducción de daños, encontraríamos el caso de la información de los consumidores de cannabis, los cuales reconocerían haber experimentado en alguna ocasión lipotimias, reacciones paranoides, arritmias o crisis agudas de ansiedad, que podrían durar desde minutos hasta horas. Y cómo un porcentaje importante de consumidores habituales de cannabis (alrededor del 20\%) confiesa que uno de los principales efectos negativos de esta sustancia sería que les produce cansancio, les baja la motivación y les quita energías (Calafat 2003).

En síntesis, con este trabajo hemos querido poner de manifiesto la necesidad de diseñar una nueva opción preventiva y educativa en la que se enfatice otro mensaje explícito en base a las verdades científicas que se derivan del uso y abuso de drogas; actuando más en su acción preventiva que sobre criterios de prohibición. Para ello, nunca deben ignorarse las motivaciones aludidas por los consumidores. Sin ol- 
vidar que éstas evolucionaron desde formas de "pasividad y huida", o "sintomatológicas", hasta los nuevos argumentos que esgrimen la búsqueda de "placer y experiencias", en relación directa a la demanda de sustancias afines a las sensaciones buscadas, que no encontradas.

\section{BIBLIOGRAFÍA CITADA}

Aitken, C.; Crofts, N. y Kerger, M. 2000. "Drivers who use illicit drugs: behaviour and perceived risks". Drugs: Education, Prevention and Policy 7 (1): 39-50.

Amigó, S. 1997. "El "problema de la droga" y la prevención del consumo de drogas: mitos y alternativas, con una especial referencia al consumo de cannabis". Alternativas 5: 157-189.

Antón, M. 1999. Las drogas: conocer y educar para prevenir. Madrid: Pirámide.

Balado, M. 1980a. "Temas sociales: El mundo de las drogas 2; efectos farmacológicos, el problema de la motivación". Las Palmas: Universidad de Las Palmas de Gran Canaria. Biblioteca Universitaria 1980-02.

Balado, M. 1980b. "Temas sociales: El mundo de las drogas 3; motivación de los consumidores, enfoque psicosociológico". Las Palmas: Universidad de Las Palmas de Gran Canaria. Biblioteca Universitaria 1980-03.

Bandy, P. y President, P. 1983. "Recent Literature on Drug Abuse Prevention and Mass Media: Focusing on Youth, Parents, Women and the Elderly”. Journal of Drug Education 13 (3): 255-271.

Baumrind, D. y Moselle, K. 1985. "A Developmental Perspective on Adolescent Drug Abuse". Advances in Alcohol and Substance Abuse 4 (3-4): 41-67.

Berrocal López, C. 2001. „El discurso psicosocial de la motivación: Representaciones sociales en torno al consumo de drogas". Flumen: Revista de la Escuela de Magisterio de Huesca 6: 55-80.

Bobes J. y Sáiz, P. 2003. "Monografía drogas de uso recreativo". www.pnsd.msc.es/Categoria2/publica/pdf/drog_recreativas.pdf. Consultada 25 de mayo de 2012.

Boys, A.; Marsden, J.; Fountain, J.; Griffiths, P.; Stillwell, G. y Strang, J. 1999. “What Influences Young People's Use of Drugs? A Qualitative Study of Decision-Making. Drugs: Education, Prevention and Policy 6 (3): 373-387.

Calafat, A. 2003. "Cannabis". Ministerio del Interior. Delegación del Gobierno para el Plan Nacional sobre Drogas. www.pnsd.msc.es/Categoria2/publica/pdf/cannbis.pdf. Consultada 22 de junio de 2012.

Cosden, M.; Basch, J.; Campos, E.; Greenwell, A.; Barazani, S. y Walker, S. 2006. «Effects of Motivation and Problem Severity on Court-Based Drug Treatment. Crime and Delinquency 52 (4): 599-618.

Costa, P. y Pérez, J. M. 1989. Drogas, televisión y sociedad. Madrid: Ministerio de Sanidad y Consumo.

Cuijpers, P.; Jonkers, D.; Weerdt, I. y De Jong, A. 2002. "The effects of drug abuse prevention at school: the 'Healthy School and Drugs' project". Addiction 97 (1): 67-73.

Dreher, M. 1983. "Marihuana and Work: Cannabis Smoking on a Jamaican Sugar Estate". Human Organization 42 (1): 1-8.

Duff, C. 2008. "The pleasure in context". Journal of Drug Policy 19 (5): 384-392.

Edis. 1988-2005. Los Andaluces ante las drogas I, II, III, IV, V, VI, VII, VIII, IX. Sevilla: Junta de Andalucía.

Edis. 2007. La población andaluza ante las drogas X. Sevilla: Junta de Andalucía.

European Monitoring Centre For Drugs And Drug Addiction. 2006. El problema de la drogodependencia en Europa: informe anual. Luxemburgo: Oficina de Publicaciones.

Fernández Ludeña, J.; Álvarez Fresno, E.; Secades Villa, R. y Jiménez García, J. M. 2003. “Consumo de drogas de síntesis en estudiantes de secundaria del Principado de Asturias (España)". Adicciones 15 (1): 31-37.

García Aurrecoechea, R. y otros autores. 2006. "Indicadores psicosociales de motivación del consumo de marihuana". Sociedad Científica Española de Estudios sobre el Alcohol, el Alcoholismo y las otras Toxicomanias.

García, F. 1996. "Influencias y efectos de los medios: la creación de estereotipos sobre la droga". Acciones e Investigaciones Sociales 4: 181-200. 
Gideon, L. 2010. "Drug Offenders' Perceptions of Motivation". International Journal of Offender Therapy and Comparative Criminology 54 (4): 597-610.

Kadushin, C.; Beveridge, A. y Livert, D. 1997. "Negative Marketing of Alcohol and Other Drugs: Some Paradoxes". Presentado al Annual Meeting of the American Sociological Association. San Francisco.

Korcha, R.; Polcin, D.; Bond, J.; Lapp, W. y Galloway, G. 2011. "Substance use and motivation: a longitudinal perspective". The American Journal of Drug and Alcohol Abuse 37 (1): 48-53.

Leon, F. 1986. "Razones atribuidas al uso de sustancias psicoactivas". Anales de Salud Mental 2 (12): $146-156$.

Longshore, D. y Teruya, C. 2006. "Treatment Motivation in Drug Users: A Theory-Based Analysis". Drug and Alcohol Dependence 81 (2): 179-188.

Lynskey, M. y Hall, W. 2000. "The Effects of Adolescent Cannabis Use on Educational Attainment: A Review". Addiction 95 (11): 1621-1630.

Measham, F. 2004. "The decline of ecstasy, the rise of 'binge' drinking and the persistence of pleasure". Probation Journal 51 (4): 309-326.

Moore, D. 2008. "Erasing pleasure from public discourse on illicit drugs: On the creation and reproduction of an absence". International Journal of Drug Policy 19 (5): 353-358.

Romaní, O. 2004. Las drogas: sueños y razones. Barcelona: Ariel.

Simoneau, H. y Bergeron, J. 2003. "Factors affecting motivation during the first six weeks of treatment". Addictive Behaviors 28 (7): 1219-1241.

Simoneau, H.; Bergeron, J.; Brochu, S. y Landry, M. 2004. "Validation of a Questionnaire on Drug Addicts' Motivation for Treatment". Drogues, Sante et Socété 3 (1): 69-106.

Spencer, C. y Navaratnam, V. 1980. "Social Attitudes, Self-Description and Perceived Reasons for Using Drugs: A Survey of the Secondary School Population in Malaysia". Drug and Alcohol Dependence 5 (6): 421-427.

Stanojlovic, M. 2011. "Análisis retórico de la publicidad institucional antidroga". Tonos Digital. Revista Electrónica de Estudios Filológicos 21. http://www.tonosdigital.es/ojs/index.php/tonos/article/ view/688. Consultada 20 de mayo de 2012.

Fecha de recepción: 31 de julio de 2012

Fecha de aceptación: 5 de julio de 2013 